\title{
RELAÇÕES DE SABER-PODER E O PROCESSO DE CONSTITUIÇÃO DO SUJEITO DEPENDENTE DIGITAL
}

\author{
Knowledge-power relationships and the process of constitution of digitally addicted \\ subject \\ Luan Alves Monteiro CARLOS \\ Universidade do Estado do Rio Grande do Norte \\ luan_alvesmonteiro@gmail.com \\ https://orcid.org/0000-0003-0442-1032 \\ Francisco Vieira da SILVA \\ Universidade Federal Rural do Semi-Árido \\ francisco.vieiras@ufersa.edu.br \\ https://orcid.org/0000-0003-4922-8826
}

RESUMO: Este artigo tem como objetivo analisar o discurso sobre o dependente digital, percebendo como os saberes e poderes atravessam a relação do sujeito com as mídias digitais. Para tanto, ancoramo-nos nas teorizações foucaultianas, sendo as reflexões desse estudioso essenciais para que possamos compreender os efeitos de sentido do discurso sobre o dependente digital. São noções como discurso, enunciado, saber, (bio) poder e biopolítica que nortearam nosso olhar sobre as materialidades estudadas. Nesse sentido, tomamos como corpus duas reportagens que circularam nas mídias digitais em diferentes portais de notícias. Trata-se de uma pesquisa descritivo-interpretativa, de abordagem qualitativa. Destarte, as análises assinalam que o discurso sobre o vício em Internet mobiliza saberes que objetivam o sujeito, ao nomear determinados hábitos como um vício, de modo a enxertar o sujeito no lugar do doente. Emergem, com isso, estratégias biopolíticas que visam a conduzir as práticas do sujeito no uso da Internet. Portanto, as instâncias de saber-poder buscam que os sujeitos atinjam um padrão de normalidade. PALAVRAS-CHAVE Dependência digital; Mídias digitais; Poder; Saber.

\begin{abstract}
This paper aims to analyze the discourse which surrounds digitally addicted subjects by comprehending how knowledge and power make their way through the relationship between a subject and the digital media. In order to do so, we land on Foucault's theories, making his reflections the essence to understand meaning effects in the discourse about the digitally addicted ones. Notions about discourse, statements, knowledge, (bio)power and biopolitics guide our look into the studied
\end{abstract}


materiality. In this regard, our corpus was composed by two reports which circulated on digital media in different news websites. This is a descriptive-interpretative research, using a qualitative approach. As consequence, the analysis revealed that the discourse about internet addiction mobilizes knowledge which objectifies the subject, when naming certain habits as addiction, in order to engraft him or her in the place of a sick person. This way biopolitical strategies that intend to conduct the subject's practices as to the use of internet emerge. Therefore, the knowledge-power instances expect the subjects to achieve a normality pattern. KEYWORDS: Digital dependence; Digital media; Knowledge; Power.

\section{FAZENDO UM LOGIN NO UNIVERSO DAS TECNOLOGIAS DIGITAIS}

O mundo analógico que ainda era possível ver no fim do século passado cedeu lugar a uma sociedade cada vez mais digital e, com isso, o novo milênio é marcado por uma velocidade, antes ainda não vista, proporcionada, na maioria das vezes, pela inserção dos aparelhos digitais na vida cotidiana. Se olharmos para os aparelhos tecnológicos, percebemos que eles vão se modernizando rapidamente. Desse modo, o que é novo no momento presente não é mais em outro, sendo substituído por aparelhos mais modernos e capazes de desenvolver coisas de uma maneira mais eficiente, o que facilita a vida em sociedade seja na comunicação e nas relações interpessoais. Não estamos alheios, porém, que há consequências negativas, como a disseminação efervescente de notícias falsas nas redes sociais, as quais podem ter resultados decisivos para um país, como no caso das eleições brasileiras em 2018. A velocidade que a contemporaneidade impõe aos sujeitos faz com que as formas de vida renovem-se rapidamente, tornando o mundo cada vez mais digital e conectado, ainda que haja discrepâncias visíveis no acesso às tecnologias, como a exclusão de muitos sujeitos à inserção no mundo digital.

Fato é que estamos vivendo uma revolução tecnológica marcada pela invenção da Internet. Partindo dessa discussão, necessitamos compreender como a Internet foi criada, para, assim, percebermos como se alcançou o nível atual de conectividade digital. A Internet originou-se de um trabalho coletivo, em que diversos sujeitos pensaram e, aos poucos, foram aperfeiçoando suas ideias até a Internet nos moldes como a conhecemos hoje. De acordo com Castells (2003), a Arpanet marca um momento importante para a formação da Internet e foi criada pela Advanced Research Projects Agency (ARPA).

AARPA era uma instituição de defesa dos Estados Unidos, que tinha por finalidade desenvolver recursos tecnológicos na época da Guerra Fria, com o objetivo de possuir uma base tecnológica militar mais eficiente e superior à da União Soviética. Esse interesse de 
reforçar as bases tecnológicas se deu após ser lançado o primeiro satélite Sputnik. Portanto, interessava ter uma defesa militar maior do que a de seu rival. No que se refere à Arpanet, convém explicitar que esse programa surgiu em um dos departamentos da ARPA, o IPTO, cujo objetivo era desenvolver uma computação interativa. Partindo deste interesse de manter uma comunicação entre os computadores, criou-se a Arpanet, para engendrar um projeto militar de defesa mais eficaz, contudo, apesar de existir essa intenção militar por traz, os criadores da Arpanet possuíam outros objetivos (CASTELLS, 2003).

Em vista disso, a Internet nasceu a partir de diferentes interesses, pois, enquanto os militares visavam a uma defesa mais eficiente, os cientistas que a desenvolveram possuíam intenções que pouco se aproximavam das estratégias militares. Sobre isso, Castells (2003, p. 21) frisa que: "Enraizou-se num sonho científico de transformar o mundo através da comunicação por computador, embora alguns dos participantes do grupo se satisfizessem em simplesmente promover boa ciência computacional". Portanto, um dos principais interesses dos cientistas era transformar a forma de se viver em sociedade; assim, desenvolviam pesquisas para descobrir novos modos de comunicação, além de aprimorar suas invenções tecnológicas, tornando o computador mais eficiente e útil. Percebemos que a possibilidade de mudar o mundo com a inserção das novidades tecnológicas é o que movia os pesquisadores a querer desenvolver suas pesquisas e impulsionar cada vez mais suas ideias.

Entretanto, o que lançou a Internet em uma dimensão planetária foi a criação da world wide web - o bastante conhecido WWW, muito usado para navegar no ambiente virtual. Esse aplicativo organizou a infinidade de sites disponíveis na rede de uma maneira acessível para o grande público, facilitando o acesso às informações. Tal criação foi realizada no CERN - que é um centro de pesquisas nucleares - por Tim Berners Lee e um conjunto de pesquisadores, possibilitando que a Internet fosse usada por toda a população. O CERN desenvolveu documentos em formato de hipertexto, os quais fizeram com que a navegação no universo digital ficasse mais simples. Com este avanço, os computadores ficaram acessíveis para toda a sociedade e passaram a fazer parte do dia a dia dos sujeitos (CASTELLS, 2007).

Com a criação da world wide web, houve uma revolução no que se refere ao uso da Internet. Contudo, inicialmente este acesso ao universo digital era ainda bem tímido. A primeira geração da web, também conhecida como web 1.0, possibilitava ao usuário poucas possibilidades de conexão. Santos e Nicolau (2012, p. 5) explicam como funcionava a web 1.0: "O que a Web 1.0 tinha de trunfo era a quantidade de informações disponibilizadas e a existência de alguns hiperlinks". Os autores continuam afirmando: 
"O que deixava a desejar era este formato ser apenas um espaço de leitura, onde o máximo de interação era a troca de e-mails entre os usuários" (SANTOS; NICOLAU, 2012, p. 5). Assim, o usuário ficava mais na posição de espectador do que já estava disponível na rede, não podendo criar seu próprio conteúdo, nem mesmo interagir com o que estava na web. Essas possibilidades de participação e de interação só foram possíveis com a chegada da web 2.0.

A web desenvolveu-se e possibilitou que o usuário se tornasse cada vez mais participativo, ou seja, se antes o sujeito era um mero espectador do que estava na rede digital, com a web 2.0 as possibilidades de interação on-line foram expandidas. Nessa perspectiva, Primo (2008, p. 101) sublinha que: “A Web 2.0 é a segunda geração de serviços on-line e caracteriza-se por potencializar as formas de publicação, compartilhamento e organização de informações, além de ampliar os espaços para a interação entre os participantes do processo". Sendo assim, esse momento da evolução digital abriu um leque de possibilidades para quem se aventura a navegar na web, pois esse espaço tornouse participativo.

Com a web 2.0, o usuário deixa de ser um mero espectador e passa a gerar conteúdo. As interações entre os sujeitos foram intensificadas, podendo travar conversas nos mais variados aplicativos, além da possibilidade de compartilhar suas ideias, comentar sobre os mais variados assuntos, ou até mesmo colocar seu dia a dia nas redes sociais por meio de fotos e vídeos. Percebemos que este momento da web é outro se o compararmos com seu início, porquanto na contemporaneidade a Internet é um lugar da participação, da interação e, principalmente, da visibilidade e é sobre esse momento que a rede digital vive que tratamos nesse artigo, mais especificamente sobre um problema que esse momento de hiperconexão trouxe para a vida dos sujeitos modernos, o vício em Internet.

Nesse sentido, este artigo tem como objetivo analisar discursos que circularam nas mídias digitais sobre a dependência digital, com vistas a compreender a relação entre o funcionamento de estratégias biopolíticas e os modos de objetivação/subjetivação do sujeito dependente digital. Nosso corpus é formado por duas materialidades que circularam na mídia digital, são elas: a) uma reportagem publicada no Correio Braziliense, intitulada Geração Z: os perigos do excesso de redes sociais para os jovens ${ }^{1}$, e b) uma reportagem publicada no G1, intitulada Tratamento psicológico combate vício em internet, celulares

\footnotetext{
1 Disponível em: <https:/www.correiobraziliense.com.br/app/noticia/revista/2016/10/03/ interna_revista_correio,551604/geracao-z-os-perigos-do-excesso-de-redes-sociais-para-osjovens.shtml>. Acesso em: 05 out. 2018.
} 
e jogos ${ }^{2}$.

Este artigo fundamenta-se nos pressupostos dos estudos discursivos foucaultianos, por meio de noções como discurso, enunciado, formação discursiva, saber, poder, biopoder e biopolítica. Dessa forma, adotamos o procedimento metodológico arquegenealógico, pois as reflexões propostas por Michel Foucault orientaram nosso olhar sobre o corpus selecionado, tendo em vista a articulação entre a emergência dos saberes sobre o sujeito hiperconectado com as relações de poder que perpassam essa construção. Trata-se também de uma pesquisa descritivo-interpretativa, em que adotamos uma abordagem qualitativa.

Destarte, este artigo organiza-se da seguinte forma: além desta discussão de caráter introdutório, refletimos, na seção a seguir, sobre algumas noções desenvolvidas por Michel Foucault; posteriormente, temos um tópico de cunho metodológico, seguidamente o tópico de análise; por fim, ponderamos acerca dos resultados alcançados com esse estudo.

\section{CONECTANDO-SE COM A TEORIA}

Os estudos foucaultianos versam sobre noções que são fundamentais para a compreensão dos discursos que circulam na nossa sociedade e que são objetos de análise de diferentes trabalhos. Nesta pesquisa, fazemos um estudo de algumas destas noções que são necessárias para o desenvolvimento de nossa análise. Sobre a arqueologia, Gregolin (2007, p. 92) indica que: "[...] ao contrário da história das ideias, a arqueologia procura apanhar o sentido do discurso em sua dimensão do acontecimento: cada palavra, cada texto, por mais que se aproxime de outras palavras e textos, nunca são idênticos aos que o precedem [...]”. Ainda segundo a autora, o método arqueológico desenvolvido por Foucault busca compreender a emergência do acontecimento discursivo, ou seja, compreender uma determinada materialidade, considerando o momento que possibilitou o seu aparecimento.

O discurso é um conjunto de enunciados que fazem parte de uma mesma formação discursiva, ou seja, todo e qualquer enunciado que fizer parte de uma regularidade, mantendo um mesmo posicionamento, forma um discurso. O discurso é então algo maior, não sendo somente aquilo que é dito em uma materialidade específica, mas é tudo que é dito em diferentes materialidades - conjunto de enunciados -, partindo de um mesmo posicionamento discursivo - formação discursiva. Assim, o discurso não pode ser confundido com enunciado, já que o discurso engloba diversos enunciados. Por exemplo, existe o discurso da medicina, e dentro deste discurso há diversos enunciados que são ditos por sujeitos especializados, e por possuírem determinado status fazem parte 
de uma determinada formação discursiva. Assim, o conjunto de enunciados dos sujeitos especialistas na área da medicina forma o discurso médico (FOUCAULT, 2016).

O enunciado deve ser percebido na singularidade de sua situação, apreendendo as suas condições de existência, a relação de um determinado enunciado com outros, além de perceber quais enunciações exclui. Nas palavras de Foucault (2016, p. 34), "[...] devese mostrar por que não poderia ser outro, como exclui qualquer outro, como ocupa, no meio dos outros e relacionado a eles, um lugar que nenhum outro poderia ocupar". Ou seja, o enunciado possui uma existência singular. Essa singularidade do enunciado é o que Foucault (2016, p. 34) chama de acontecimento discursivo: "Por mais banal que seja, por menos importante que o imaginemos em suas consequências, por mais facilmente esquecido que possa ser após sua aparição [...] um enunciado é sempre um acontecimento [...]". O enunciado é um acontecimento que se liga a outros enunciados que o precedem e o sucedem, abrindo para si um campo de uma memória, sendo único como acontecimento, mas sempre aberto a repetições e transformações (FOUCAULT, 2016).

Essa relação existente entre os enunciados leva Foucault (2016) a versar sobre as formações discursivas. Segundo o autor, quando se puder observar uma regularidade entre os objetos, enunciações, conceitos e temas trata-se de uma formação discursiva. Assim, quando um conjunto de enunciados mantém uma relação entre si, uma singularidade, abordando sobre um mesmo objeto, defendendo um mesmo posicionamento discursivo, esses enunciados fazem parte de uma mesma formação discursiva, sendo essa noção usada para se referir a um semelhante sistema de dispersão. Partindo desse conceito, o autor atenta para as regras de formação de uma dada formação discursiva, quais sejam: as formações dos objetos, das modalidades enunciativas, dos conceitos e das estratégias. Essas são as condições de existência dos discursos, e é quando discute sobre essas unidades que Foucault (2016) trata sobre o aparecimento, transformação e desaparecimento dos discursos. As duas primeiras unidades discutidas pelo autor irão orientar o nosso olhar sobre o objeto da presente pesquisa. Desse modo, para fins de análise, faz-se necessário aprofundar o estudo sobre esses dois conceitos.

A formação dos objetos diz respeito aos objetos que os discursos se ocupam a descrever. Para explicar esse fenômeno, Foucault (2016) analisa o discurso da psicopatologia e, a partir de questionamentos sobre as regras de aparecimento e o regime de existência dos objetos, o filósofo delineia três fases de análise: inicialmente Foucault (2016) fala sobre as superficies primeiras de emergência, que se detêm em mostrar onde podem surgir os objetos, para que possam ser analisados e qualificados. Convém frisar que essas superfícies mudam de acordo com a sociedade e a época. Depois, o filósofo fala 
das instâncias de delimitação, que são instâncias superiores (medicina, justiça, religião), as quais possuem uma qualificação que as tornam competentes a distinguir, designar e nomear os objetos. Finalizando, o autor trata das grades de especificação, que são compreendidas como os sistemas que separam, opõem, associam e classificam os objetos.

No que se refere à formação das modalidades enunciativas, Foucault (2016) indica que o discurso não pode vir de qualquer sujeito, pois quem fala tem que estar autorizado a fazê-lo, ou seja, o sujeito deve possuir uma qualificação e um status que lhe dê competência para proferir determinados discursos, sendo esta qualificação necessária para que seu discurso seja tomado como verdade ${ }^{3}$. Essa questão é exemplificada por Foucault (2016) por meio da fala médica, a qual não pode ser proferida por um sujeito qualquer, porquanto sua eficácia como fala médica está associada ao sujeito que possui um status que o qualifica a proferir tal discurso. É necessário também atentarmos para o lugar institucional de onde o sujeito obtém seu discurso; no caso do médico, esse lugar é o hospital. Ademais, é imperativo perceber as posições que o sujeito ocupa no discurso. Essas posições são assumidas quando o sujeito questiona, ouve, observa, anota, ou seja, o sujeito assume um posicionamento com relação ao objeto do discurso.

Sobre o seu período arqueológico, Foucault (2016) evidencia que: "Em vez de percorrer o eixo consciência-conhecimento-ciência (que não pode ser liberado pelo índex da subjetividade), a arqueologia percorre o eixo prática discursiva-saber-ciência" (FOUCAULT, 2016, p. 220). Diferentemente da história das ideias que se interessa pelo conhecimento, a arqueologia analisa o saber, ou seja, os estudos arqueológicos analisam o sujeito em um domínio em que ele é sempre situado e dependente. O filósofo enfatiza ainda que a prática discursiva que forma os saberes não é somente o que é dito no campo científico. Para o autor: "O saber não está contido somente em demonstrações; pode estar também em ficções, reflexões, narrativas, regulamentos institucionais, decisões políticas" (FOUCAULT, 2016, p. 221).

Ou seja, o saber não é formado somente no campo da ciência, mas também fora deste campo, de modo que todos discursos possuem um saber que possibilita o seu aparecimento. Segundo Revel (2005), subsiste uma exigência para que os sujeitos

\footnotetext{
${ }^{3}$ É importante considerar que a verdade do saber médico tem sido cada vez mais colocada sob suspeita, tendo em vista haver esferas da vida humana que parecem estar mais expostas à presença simultânea de discursos produzidos por indivíduos que não possuem o status devido, mas que, mesmo assim, impactam de maneira substancial a vida em sociedade. Podemos citar como exemplo toda a celeuma produzida pelo Presidente da República do Brasil, Jair Bolsonaro, diante da pandemia da Covid-19, ao estimular uma medicação que não possui uma comprovação científica para o tratamento da doença.
} 
produzam um discurso sobre si, para revelar sua existência (desde questões profissionais até afetivas), sendo a vida objeto do saber. A vida dos sujeitos é revelada ao outro - por meio da observação das condutas, do ouvir as verdades do outro - e, assim, o saber é produzido.

Ao falar sobre o objetivo dos seus estudos, Foucault (2009a) ressalta que, apesar de ter se dedicado bastante à questão do poder, não era seu objetivo analisá-lo, mas, sim, o sujeito. Conforme Foucault (2009a, p. 231), seu interesse "foi criar uma história dos diferentes modos pelos quais, em nossa cultura, os seres humanos tornaram-se sujeitos". Para estudar o sujeito, o autor procurou perceber como esse é objetivado. No entanto, faz-se necessário estudar o poder para compreender o processo de objetivação do sujeito.

Segundo Foucault (2009a), existem três modos de objetivação, são eles: o modo da investigação, as práticas divisoras e o modo pelo qual um ser humano torna-se um sujeito. Para nossa pesquisa necessitamos discutir um desses modos que são as práticas divisoras. Tais práticas dividem os sujeitos entre aqueles que possuem determinadas características consideradas normais, e, por isso, são incluídos na sociedade, e aqueles que possuem características consideradas negativas e, por conta disso, são excluídos. Percebemos que a objetivação do sujeito efetiva-se em um processo de inclusão e exclusão, ao mesmo tempo em que inclui o sujeito sadio, exclui o doente.

É importante perceber que não existe o lugar do poder, alguém que detém o poder, o que existe são relações de poder presentes por toda parte da sociedade. Não devemos pensar que o Estado é a instância detentora do poder, ou que esse é um mecanismo de dominação entre os indivíduos. Desse modo, não existem sujeitos que possuem o poder enquanto um bem e outros que dele são absolutamente alijados (FOUCAULT, 2017).

Em Vigiar e Punir, Foucault (2009b) trata sobre o poder disciplinar que é exercido pelas instituições (escolas, famílias, fábricas, hospitais, quartéis). Esse tipo de poder está presente em toda sociedade e busca controlar os corpos, tornando-os disciplinados, dóceis e, consequentemente, mais úteis. Esse é o poder que visa ao aperfeiçoamento dos corpos, tornando-os mais capazes para, por exemplo, produzir mais e melhor nas fábricas e aumentar a utilidade. Interessa, para essa modalidade de poder, ter corpos dóceis e submissos, a fim de que se tenha um controle cada vez maior. Dessa forma, pode-se ter um sistema carcerário mais eficiente, operários mais produtivos, ou seja, dentro dos muros de tais instituições esse poder é exercido, existindo um controle sobre os corpos dos sujeitos que regula o que se faz e o que se deixa de fazer.

Percebemos que a disciplina recai sobre os corpos dos sujeitos para obter a sua força de trabalho, ou seja, é um poder que recai sobre o corpo máquina. Por outro lado, 
existe a biopolítica que também age sobre os corpos, mas seu interesse é controlar a vida, criando estratégias que visam fazer funcionar o fazer viver. Para isso, é exercido um cuidado com a saúde. De acordo com o autor supracitado, essas tipologias de poder, apesar de distintas, são também complementares. Podemos ver que, dentro do mecanismo da biopolítica, existe a atuação de um poder disciplinar. Observemos o que Foucault (2010, p. 152) fala sobre o funcionamento do biopoder:

\footnotetext{
Desenvolvimento rápido, no decorrer da época clássica, das disciplinas diversas - escolas, colégios, casernas, ateliês; aparecimento também no terreno das práticas políticas e observações econômicas, dos problemas de natalidade, longevidade, saúde pública, habitação e migração; explosão, portanto, de técnicas diversas e numerosas para obterem a sujeição dos corpos e o controle das populações. Abre-se, assim, a era de um "bio-poder".
}

Essa técnica de poder parte de diversos lugares da sociedade para disciplinar os corpos, para produzir sujeitos produtivos, mas a sua atuação vai além disso quando se preocupa com a qualidade de vida da população, incidindo, assim, sobre o corpo espécie. Nesse sentido, no funcionamento do biopoder, observamos um interesse político que objetiva moldar corpos fortes e saudáveis para se ter trabalhadores eficientes, mas também busca informar a população sobre possíveis comportamentos que podem levar a uma determinada doença. Desse modo, há medidas preventivas para que os sujeitos não venham a adoecer e, consequentemente, produzir gastos de ordem privada ou estatal.

\section{PERCURSO METODOLÓGICO}

Este artigo constitui um recorte de um estudo maior, em desenvolvimento por meio de um trabalho de mestrado do primeiro autor sob a orientação do segundo. Na dissertação, analisamos dez materialidades discursivas presentes na web, as quais se configuravam no formato de reportagens, notícias, informativos de clínicas médicas, dentre outros, os quais tinham como semelhança a constituição de discursos sobre o sujeito dependente digital. O material foi coletado no segundo semestre do ano de 2018, junto aos mecanismos de buscas do Google por meio das entradas dependente digital e viciado em Internet. Para este artigo, selecionamos como corpus duas reportagens que deixam entrever, de modo mais evidente, a relação entre a dependência digital e a constituição de um saber médico que objetiva o sujeito dependente. Esse, portanto, foi o critério de escolha para a seleção dessas duas reportagens. Para extrair os excertos que nos interessavam, fizemos uma 
leitura prévia do material e identificamos quais passagens deixavam entrever a relação entre o diagnóstico médico e a emergência do sujeito dependente, conforme veremos no tópico a seguir.

\section{VISUALIZANDO O PERFIL DO DEPENDENTE DIGITAL: A PATOLOGI- ZAÇÃO DO SUJEITO VICIADO}

Este tópico concentra-se em analisar materialidades que circularam nas mídias digitais que discursivizam saberes sobre o sujeito hiperconectado. Nesse sentido, deter-nos-emos em analisar o discurso de sujeitos que possuem status que os qualifica a dar diagnósticos, ou seja, pretendemos perceber como o sujeito dependente digital é objetivado pelo discurso médico.

Em uma reportagem publicada no Correio Braziliense, intitulada Geração Z: os perigos do excesso de redes sociais para os jovens, escrita pelo neurologista Ricardo Teixeira, portanto um sujeito autorizado a falar, conforme as modalidades enunciativas descritas por Foucault (2016). O posicionamento discursivo assumido na reportagem vê a hiperconexão como um problema. Como corolário dessa questão, temos, por exemplo, a chamada nomofobia, ou seja, o pavor de estar distante de celulares e/ou outros aparelhos eletrônicos como tablets e laptops. Dessa forma, a reportagem discursiviza sobre os riscos decorrentes das práticas desempenhadas on-line e pontua que esse excesso de interação com o virtual acontece principalmente entre os adolescentes. A materialidade chama a atenção para usos considerados problemáticos de Internet, dando destaque para situações em que as relações sociais do usuário resumem-se a interações mediadas por computadores e smartphones. É em atitudes como esta que o sujeito discursivo atesta o risco, o problema. A posição enunciativa frisa que:

Vida social é uma ferramenta fundamental para nosso estado de felicidade e até mesmo de saúde. Mas será que os amigos virtuais têm esse mesmo poder? Parece que não. Pesquisas têm revelado uma associação entre o tempo gasto no Facebook e sintomas depressivos. Aí vem a velha pergunta de ovo ou galinha? A resposta mais provável é que o excesso de tempo nas redes sociais possa ser tanto a causa como consequência dessa maior frequência de sintomas psiquiátricos (CORREIO BRAZILIENSE, 2016, s. p.).

A posição de sujeito ressalta algumas benesses que a vida em sociedade proporciona ao sujeito, citando benefícios relacionados à felicidade e à saúde, ou seja, ter uma boa 
convivência é algo essencial para se viver bem. Logo, o enunciado chama atenção para situações em que esse convívio acontece no virtual: "Mas será que os amigos virtuais têm esse mesmo poder? Parece que não". Enquanto as interações que acontecem off-line são apresentadas como algo saudável, as relações mantidas on-line são discursivizadas como algo ruim, o sujeito que enuncia assume um posicionamento que vê uma relação entre o uso exagerado de Internet com problemas de saúde: "Pesquisas têm revelado uma associação entre o tempo gasto no Facebook e sintomas depressivos". Nesse sentido, a voz que fala delineia malefícios causados pelo excesso de conexão, através das instâncias de delimitação ("pesquisas") que designam a dependência digital como um objeto de discurso. Compreendemos, então, que o uso excessivo de Internet é algo problemático, pois atinge o sujeito não só no momento em que a interação virtual acontece, mas também interfere na vida do sujeito como um todo. Como no exemplo citado, em que problemas de depressão surgem como consequência do excesso de conexão com o virtual, esta doença adquirida pode comprometer a realização de diversas atividades que são desenvolvidas fora do universo on-line. O uso desregrado de Internet é discursivizado pelo saber médico como algo prejudicial à saúde. Isso nos leva a Foucault (2009a), quando pensa nas práticas divisoras. Para o autor, há a divisão entre o normal e o anormal e, no caso em análise, tem-se a distinção entre os sujeitos que fazem um uso saudável do ambiente on-line e os que exageram esse uso. Desse modo, a materialidade sublinha ainda que:

Causa? Podemos pensar que uma pessoa exagerada e compulsiva tem problemas no controle de seus impulsos. E essa dificuldade em controlar os impulsos pode ter reflexos em várias dimensões da sua vida. E os adolescentes dão goleada quando se fala em impulsividade. Um estudo conduzido nos EUA mostrou que eles trocam uma média de 109 mensagens diárias pelo celular enquanto os adultos ficam com uma média de dez mensagens por dia (CORREIO BRAZILIENSE, 2016, s. p.).

A posição de sujeito continua pontuando alguns prejuízos provenientes do uso compulsivo de Internet, dando destaque a atitudes como exageros e falta de controle de impulsos. Esses comportamentos podem explicar uma possível dependência da Internet, pois o sujeito não consegue se controlar e acaba acessando o virtual por tempos cada vez maiores, daí a compulsão. Além disso, a posição de sujeito frisa que atitudes impulsivas são percebidas principalmente entre os adolescentes. Sobre o comportamento on-line dos adolescentes a materialidade destaca que: "Um estudo conduzido nos EUA mostrou que eles trocam uma média de 109 mensagens diárias pelo celular enquanto os adultos ficam 
com uma média de dez mensagens por dia". Esse aspecto comparativo constitui uma grade de diferenciação, conforme nos lembra Foucault (2016), pois permite separar e opor o uso desregrado da web por parte do sujeito adolescente e o uso mais moderado feito pelos adultos.

Os resultados do estudo exemplificam atitudes que demonstram a compulsão e compõem os modos de investigação, de que fala Foucault (2009a). Para tanto, toma como base atividades como a troca de mensagens, observando que entre os adolescentes essa prática é realizada um número maior de vezes se comparado com a quantidade de mensagens trocadas pelos adultos. Esse excesso de interações mediadas pelo ambiente virtual é visto pela posição sujeito como algo prejudicial; além disso, destaca um agravante quando se trata da população mais jovem. Sendo assim, a voz que fala indica que existe uma diferença de comportamento entre os sujeitos de faixas etárias diferentes no que se refere ao contato com a Internet. Compreendemos, então, que os adolescentes possivelmente estão mais vulneráveis a um possível vício em Internet. O enunciado indica também consequências que o vício em Internet pode causar:

Conseqüência? Redes sociais provocando mal estar psíquico? Uma forma de explicar essa ligação é o efeito comparativo com os outros "amigos" que só expõem os louros do cotidiano e isso pode fazer com que a pessoa sinta que tem um projeto de vida mal-sucedido. Além disso, a prática virtual exagerada pode reduzir os encontros em carne e osso, o que pode desestabilizar o equilíbrio psíquico.

Se esses fatores são relevantes para um adulto, imagine só para o cérebro de um adolescente que ainda está em formação! Alguns deles têm sinais típicos de dependência quando afastados do seu vício eletrônico. Pesquisas mostram que meninos e meninas digitam com a mesma frequência nas redes sociais, mas os exageros acontecem mais com as meninas. E esse exagero está associado a um menor desempenho acadêmico, mais sintomas depressivos, maior exposição ao álcool e outras drogas e também experiência sexual mais precoce (CORREIO BRAZILIENSE, 2016, s. p.).

$\mathrm{Na}$ materialidade são discursivizados sintomas oriundos das práticas executadas on-line. É dado destaque a problemas relacionados à esfera mental do sujeito, de modo a indicar o mal-estar e também desequilíbrio psíquico como consequência das interações que acontecem on-line. A posição enunciativa vê a hipervisibilidade inerente a sites de redes sociais como um dos grandes causadores de patologias geradas pela conexão com o virtual. Isso acontece porque, ao adentrar na Internet, o sujeito se depara com diversas realidades e o tipo de conteúdo mais compartilhado em sites como o Facebook é a vida dos 
próprios usuários que é publicizada por meio de fotos e vídeos. Nesse sentido, verificamos que o agravante desse tipo de interação é que, na maioria das vezes, só são mostrados momentos bons de suas vidas. Assim, quando o sujeito que visualiza tais conteúdos compara a realidade exposta na postagem com a sua vida passa a achar que possui uma vida ruim. Por meio desse tipo de comparação o problema é gerado, pois o sujeito não consegue ter uma vida como a que é exibida por seus amigos e passa a desenvolver patologias, como, por exemplo, o mal-estar psíquico, conforme apontado na reportagem. Destarte, compreendemos então que não é só o tempo gasto on-line ou o prazer gerado por estar conectado que é visto como um problema, mas também o conteúdo consumido, o que pode gerar problemas de saúde.

O sujeito discursivo indica ainda outro problema que o excesso de conexão com o virtual causa: “[...] a prática virtual exagerada pode reduzir os encontros em carne e osso, o que pode desestabilizar o equilíbrio psíquico". O grande interesse pelo que se passa no ambiente on-line pode acarretar um afastamento dos sujeitos no que se refere ao espaço off-line. Essa relação constrói a dependência através de superfícies primeiras de emergência que nomeiam a dependência digital como um objeto de discurso. Esse tipo de comportamento é apontado como o causador de doenças como o desequilíbrio psíquico, ou seja, são comportamentos adquiridos graças à dependência digital e que afetam a convivência do sujeito com o espaço à sua volta. A posição que enuncia na materialidade destaca ainda que existe uma diferença no modo como a tecnologia atinge o público de diferentes faixas etárias, assinalando que existe um interesse pelos eletrônicos por parte dos adultos. Mas, sinaliza um agravante quando se trata dos adolescentes, indicando que eles são mais propensos a se deter aos encantos proporcionados pelo virtual. Assim, os sujeitos mais jovens possuem uma maior tendência em desenvolver o vício em Internet.

Reconhecemos que a construção discursiva trata de um problema da contemporaneidade. Desse modo, atinge de maneira mais veemente os mais jovens que, na maioria das vezes, sempre estiveram em contato com o digital, diferentemente dos adultos que viveram em uma época em que as plataformas digitais não existiam ou não eram tão populares. Percebemos que os saberes tornam visível o vício em Internet, de modo a chamar atenção para o problema. Para tanto, o enunciado informa sobre comportamentos que o saber qualifica como problemáticos, indicando situações que expõem o sujeito usuário a situações de risco. Ao descortinar a patologia, apresentando os efeitos danosos de determinados usos de Internet, a posição de sujeito sugere que os hábitos mudem, para que se tenham sujeitos saudáveis e normalizados.

Dentre os comportamentos tidos como problemáticos, é dado destaque aos 
exageros que são cometidos na conexão virtual. Assim, o sujeito enunciativo frisa: "E esse exagero está associado a um menor desempenho acadêmico, mais sintomas depressivos, maior exposição ao álcool e outras drogas e também experiência sexual mais precoce". Os excessos empreendidos no virtual refletem diretamente na vida do sujeito, interferindo nos estudos, na saúde, bem como influenciando que novos hábitos sejam desenvolvidos como o uso de álcool e drogas. Ademais, pode influenciar também na vida sexual do adolescente. Em outras palavras, ao se deter a atividades mediadas pela Internet, o sujeito fica mais exposto a conteúdos a que, muitas vezes, não teria acesso fora do ambiente virtual. Nessa perspectiva, determinados conteúdos influenciam que se realizem determinadas práticas que vão desde o uso de drogas até uma iniciação sexual precoce. Isso também impede que o sujeito se dedique a outras atividades, como o estudo, levando-o a ter um menor desempenho escolar.

Ao descrever as causas e as consequências do uso desenfreado de Internet, a posição de sujeito informa a população sobre os riscos existentes nas interações que são travadas on-line. Para tal, utiliza-se da fala médica, ou seja, busca o discurso de sujeitos autorizados para que o que é dito seja tomado como verdade. Assim, são mobilizados saberes para descrever comportamentos que atestam a compulsão pelos eletrônicos; além disso, esse discurso visa a esclarecer sobre os sintomas os quais surgem como consequência de um uso descontrolado de Internet. Resumindo, o discurso médico objetiva o dependente digital, colocando-o no lugar do enfermo.

$\mathrm{Na}$ reportagem publicada no portal de notícias G1, intitulada Tratamento psicológico combate vício em internet, celulares e jogos, percebemos que, desde o título, a posição que enuncia chama a atenção para a patologização do sujeito, ao evidenciar o tratamento, bem como ao denominar como vício determinadas práticas realizadas na Internet. Dessa forma, entendemos que se trata de um discurso que mobiliza saberes acerca de um problema de saúde que atinge a população contemporânea. Além disso, busca viabilizar uma possível solução para o problema ao sinalizar para o combate. Assim, a posição enunciativa delineia desde os sintomas, até o modo como o vício pode ser identificado e tratado, observemos alguns dados que a materialidade traz à baila, o que nos permite perceber como se organiza o cenário do uso de Internet no Brasil:

Em abril deste ano, uma pesquisa do Instituto Brasileiro de Geografia e Estatística (IBGE) apontou que o celular se tornou o principal meio de acesso à internet no Brasil. Essa facilidade, sobretudo para os mais jovens, tem trazido a reboque um problema: as pessoas passaram a dedicar cada vez mais tempo aos smartphones e a relegar a segundo 
plano algumas tarefas do dia a dia. Esse fato, segundo especialistas da área de psicologia, pode causar problemas no convívio social e familiar (G1, 2016, s. p.).

Os dados apresentados pela voz que enuncia partem de um lugar institucional autorizado (FOUCAULT, 2016), o IBGE, sendo este um instituto que ouve, observa e questiona a população para realização de um censo sobre a mesma, de modo a engendrar dados que possuem um valor de verdade. Dessa forma, esse saber estatístico, ao informar que o celular é o principal meio usado para ter acesso à Internet, deixa entrever que esse aparelho facilitou o acesso ao virtual o que, consequentemente, torna a população mais vulnerável aos possíveis danos causados pela conexão com sites de redes sociais e jogos. Ou seja, averiguamos que a facilidade para se conectar proporcionada principalmente com a popularização dos smartphones, permite que se prolifere um uso problemático. Tal fato leva os sujeitos a se voltar cada vez mais ao ambiente on-line, o que acarreta um afastamento das interações fora da rede virtual.

Esse acesso facilitado das plataformas digitais é apontado pela voz que fala como um impulsionador para que se tenha um número maior de casos de vício em Internet. Ecoa nesse discurso a voz de especialistas da área da saúde, tais como psicólogos, que sinalizam para problemas familiares que surgem em decorrência das interações mantidas no virtual. Reconhecemos, nesse discurso, a recorrência de um afastamento da realidade fora da rede, o que gera problemas para a vida do sujeito viciado. Sendo assim, é possível observar que a patologia se desenvolve quando a realidade virtual passa a interferir e prejudicar a realidade fora do espaço digital. A posição enunciativa sublinha alguns sintomas que denunciam a presença do vício:

"A modificação de humor, por exemplo. Eu me sinto irritado, ansioso, chateado, quando interrompo o uso. É um sintoma. Eu despendo muito tempo em tecnologia é um segundo. Pessoas próximas a você, familiares, um namorado, uma namorada, reclamam sobre o uso. Tu alteras teu sono por causa disso, deixa os estudos de lado... Quando a gente junta uma série de sintomas, a gente pode cogitar a possibilidade de que aquela pessoa seja dependente de celular, internet e de jogos eletrônicos", explicou o especialista (G1, 2016, s. p.).

O sujeito autorizado a enunciar (FOUCAULT, 2016), o psicólogo Igor Lemos, discursiviza alguns sintomas. Nesse sentido, são considerados pelo saber médico como problemáticos comportamentos que vão desde a dificuldade que o sujeito tem para se 
distanciar das tecnologias digitais, sendo que são apontados sinais como: a variação de humor, ansiedade, irritabilidade, sendo estes sintomas apresentados pelo sujeito ao ficar longe dos aparelhos digitais, até o excesso de tempo voltado para a realidade virtual. Verificamos que tais indícios estão associados entre si, pois se o sujeito não se sente bem ao ficar longe da Internet, consequentemente acaba passando mais tempo on-line. Outros sintomas enfatizados são as reclamações de sujeitos de seu convívio diário. Podemos perceber que essas reclamações estão associadas a um possível afastamento do sujeito de suas relações com quem está próximo. Além disso, destacam-se as mudanças na rotina, como, por exemplo, interromper o horário de dormir para ficar conectado, bem como o uso da Internet com interferência no desenvolvimento dos estudos. Ao elencar tais sintomas, o sujeito especialista sinaliza que, ao identificar essas atitudes, possivelmente se chega a um diagnóstico de dependência. Ao levar essa informação ao público, a posição enunciativa pretende que o problema seja identificado para que, a partir disso, o sujeito possa buscar uma solução.

Subsiste nesse discurso um interesse biopolítico (FOUCAULT, 2010), pois, ao informar, para que se possa reconhecer e tratar o problema, tem-se um alerta para a população. Isto é, ao ser discursivizadas algumas atitudes que denunciam uma possível presença da patologia, os sujeitos inevitavelmente passam a observar suas práticas no virtual ficando atentos para identificar se possuem algum sintoma. Nesse sentido, a partir desse reconhecimento do problema, o sujeito passa a desenvolver práticas de si, para atingir uma normalidade exigida pelos saberes e poderes que perpassam a relação do sujeito com o digital.

Sendo assim, esses saberes, ao serem enunciados, visam a despertar no sujeito um cuidado de si (FOUCAULT, 2006), o que o possibilita subjetivar-se ao passo que muda seus hábitos, deixando de lado a forma que interagia on-line, aderindo um uso mais consciente, conforme os saberes indicam como um uso adequado do digital. A partir dos saberes sobre o vício em Internet, os poderes agem sobre as ações dos sujeitos, exercendo uma disciplina dos corpos, conforme podemos verificar na materialidade:

As crianças, que no mundo moderno, vêm substituindo brincadeiras e atividades físicas pelos jogos eletrônicos e a internet devem receber atenção especial, segundo Igor Lemos. "o que é recomendado pela sociedade de psiquiatria e também de pediatria americana é sobre duas horas ao dia. As crianças devem usar mais ou menos esse tempo com mídias eletrônicas. Para o começo, quando começar a utilizar tecnologia, depende muito da dinâmica de cada família. Algumas permitem com dois, três anos de idade, outras para oito ou nove anos", explica. 
O psicólogo afirma, contudo, que o principal é que os pais estejam sempre presentes e no domínio da situação. "O que é mais importante como critério é a família supervisionar. Ou seja, monitorar esse uso e não utilizar também a tecnologia como uma forma de lidar com frustração. A criança faz uma birra, começa a se estressar, você dá o artefato, dá para ela o celular, dá para ela o jogo. Ela se acalma, você repete esse hábito, e aí você cria uma criança intolerante à frustração e isso é um problema", pondera (G1, 2016, s. p.).

O sujeito que possui um status que o qualifica a enunciar, o psicólogo Igor Lemos descreve situações, as quais demonstram que existe uma predileção pelos jogos e as interações na Internet, em detrimento das diversões que acontecem fora da seara dos eletrônicos. Verificamos um uso problemático das tecnologias digitais, tanto por se tratar de crianças, ou seja, o sujeito volta-se para os aparelhos digitais de forma precoce, quanto pelo fato de existir uma substituição das diversões e atividades físicas por uma conexão com o espaço virtual. Ao informar sobre esse tipo de uso, a posição enunciativa deixa entrever que desde cedo pode haver um uso inadequado e possivelmente abusivo do digital, o que aumenta a possibilidade de um futuro vício. Lembrando Foucault (2009a), esse saber da psicologia que produz um alerta em relação aos usos e abusos do digital faz com que a criança torne-se um sujeito sobre o qual é preciso intervir.

O sujeito especialista obtém seu discurso a partir de instituições, como a sociedade de psiquiatria e de pediatria. O posicionamento discursivo desse lugar institucional de onde parte o saber especializado recomenda um tempo de duas horas por dia de conexão para as crianças. Ao estabelecer esse tempo, esse lugar de fala dissemina o saber, ao mesmo tempo em que exerce um poder que disciplina os sujeitos (FOUCAULT, 2009b), ao regular o tempo que as crianças podem estar conectadas. Essa atuação de um poder disciplinar continua sendo percebida quando, ao indicar que os pais devem decidir quando a Internet deve ser apresentada para as crianças, nesse caso, a disciplina passa a ser exercida também pela instituição familiar.

O controle continua sendo exercido ao ser orientado que os pais acompanhem o uso feito pelos filhos. Reiteramos que o sujeito autorizado a falar utiliza-se de uma posição de prestígio para orientar os sujeitos, conduzindo as condutas dos adultos e das crianças. Ademais, sinaliza para a supervisão das práticas desempenhadas on-line, o tempo que se passa na rede e o momento de se apresentar as tecnologias digitais para as crianças. Já o controle exercido sobre os adultos ocorre ao sublinhar que não se deve utilizar os aparelhos digitais para entreter as crianças em situações de adversidades. Ou seja, para solucionar situações de estresse da criança, os pais muitas vezes se utilizam das 
tecnologias digitais para apaziguar a situação, o que impossibilita a criança de lidar com frustação. Além disso, leva o sujeito a ter um excesso de uso desde cedo. Dessa forma, entendemos que esse hábito pode acompanhar o sujeito até a vida adulta, e isso pode gerar um possível vício.

\section{CONEXÕES FINAIS}

Após compreendermos os efeitos de sentido presentes nos enunciados analisados neste artigo, percebemos como o sujeito dependente digital é objetivado por saberes e poderes que perpassam as práticas desempenhadas no virtual. Os enunciados analisados mobilizam saberes oriundos da área médica, os quais qualificam determinadas práticas como nocivas à saúde dos sujeitos, ao mesmo tempo em que indicam as consequências que tais práticas desencadeiam. Dessa medida, é assumido um posicionamento discursivo que reprova alguns comportamentos, mas que também sinaliza alguns modos saudáveis de conviver com as tecnologias. As instâncias de delimitação (FOUCAULT, 2016), no caso, a medicina, discursivizam sintomas os quais possibilitam que o problema seja diagnosticado e, com isso, produzem processos de objetivação, ao inserir o sujeito viciado no lugar do enfermo, que necessita de tratamento especializado.

A relação do sujeito com a Internet é esquadrinhada por saberes e poderes que perpassam todas as atividades executadas on-line. Trata-se de um poder que age sobre as ações dos outros, caminhando entre o combate e a prevenção, pois interessa evitar que os sujeitos se tornem viciados em Internet e, nos casos em que o vício já existe, busca-se a regeneração dos corpos. Dessa forma, os enunciados analisados, por meio de relações de saber-poder, impulsionam os sujeitos a quererem entrar em um padrão de normalidade, de acordo com o que os saberes dizem que é o saudável. Portanto, na ordem do dizível o que interessa é o corpo saudável. A objetivação do sujeito acontece quando este passa a ser nomeado pelos saberes como o dependente digital, ser reconhecido pela área médica como o doente. Além disso, quando passa a ser exercido um controle sobre seus hábitos, tendo suas ações esquadrinhadas pelo exercício de poderes que se encontram pulverizados na sociedade. Essas são práticas de saberes e poderes que buscam despertar no sujeito um cuidado de si.

Esses apontamentos sinalizam para um quadro social em que a preponderância das tecnologias digitais torna-se danosa para a saúde nas mais diferentes formas. As materialidades analisadas mostram-nos como as relações de saber e de poder constroem o sujeito dependente digital e como esse discurso de alerta constitui uma prática que visa a 
dirimir as consequências perniciosas do problema. Acreditamos que é preciso atentar para essas sinalizações de perigo no uso do digital, na medida em que estamos tão envolvidos em tal jogo, a ponto de não darmos conta de que também podemos fazer parte desse quadro de dependência. Noutras palavras, a naturalidade com que tratamos os artefatos digitais, tomados como uma espécie de extensão dos nossos corpos, implica o reordenamento de nossas subjetividades e pode nos afastar de relações mais sólidas e contatos mais firmes e duradouros que nem sempre essas tecnologias podem nos ofertar. 


\section{REFERÊNCIAS:}

CASTELLS, Manuel. A galáxia da internet: reflexões sobre a internet, os negócios e a sociedade. Rio de Janeiro: Zahar, 2003.

. A sociedade em rede. São Paulo: Paz e Terra, 2007.

CORREIO BRAZILIENSE. Geração Z: os perigos do excesso de redes sociais para os jovens. 2016. Disponível em: https://www.correiobraziliense.com.br/app/noticia/ revista/2016/10/03/interna_revista_correio,551604/geracao-z-os-perigos-do-excesso-deredes-sociais-para-os-jovens.shtml. Acesso em: 23 mar. 2019.

FOUCAULT, Michel. O sujeito e o poder. In: DREYFUS, H. L.; RABINOW, P. Michel Foucault: uma trajetória filosófica para além do estruturalismo e da hermenêutica. Rio de Janeiro: Forense Universitária, 2009a, p. 231-250.

. Vigiar e punir: nascimento da prisão. Petrópolis: Editora Vozes, 2009b.

. A hermenêutica do sujeito. São Paulo: Martins Fontes, 2006.

2010.

História da sexualidade I: a vontade de saber. Rio de Janeiro: Edições Graal,

. A arqueologia do saber. Rio de Janeiro: Forense Universitária, 2016.

Soberania e disciplina. In: FOUCAULT, Michel. Microfísica do poder. Rio de Janeiro/São Paulo: Paz e terra, 2017, p. 278-295.

G1. Tratamento psicológico combate vício em internet, celulares e jogos. 2016. Disponível em: http://g1.globo.com/pernambuco/noticia/2016/07/tratamento-psicologico-combatevicio-em-internet-celulares-e-jogostm.html. Acesso em: 23 mar. 2019.

GREGOLIN, Maria do Rosário. Foucault e Pêcheux na análise do discurso: diálogos \& duelos. São Carlos: Editora Claraluz, 2007.

PRIMO, Alex. O aspecto relacional das interações na web 2.0. In: ANTOUN, Henrique. Web 2.0: participação e vigilância na era da comunicação distribuída. Rio de Janeiro: Mauad X, 2008, p. 101-122.

REVEL, Judith. Michel Foucault: conceitos essenciais. Tradução Maria do Rosário Gregolin, Nilton Milanez, Carlos Piovesani. São Carlos: Claraluz, 2005. 
SANTOS, Emanuella; NICOLAU, Marcos. Web do futuro: a cibercultura e os caminhos trilhados rumo a uma Web semântica ou Web 3.0. Revista Temática (UFPB), João Pessoa, v. 8, n. 10, p. 1-14, 2012.

Recebido em: 20 mar. 2020.

Aceito em: 21 mai. 2020. 